\title{
Volumetric Laser Endomicroscopy
}

National Cancer Institute

\section{Source}

National Cancer Institute. Volumetric Laser Endomicroscopy. NCI Thesaurus. Code C140327.

An endoscopic imaging technology that uses optical coherence tomography with near infrared light and balloon-centered imaging probes to produce scans of $6 \mathrm{~cm}$ segments of the esophagus, with surface and subsurface image depth greater than $3 \mathrm{~mm}$ with 7 micron axial resolution. These high-speed scans allow real-time diagnosis of surface and subsurface abnormalities and can guide endoscopic treatment. 